\title{
Quality of life in a real-world cohort of advanced breast cancer patients: a study of the SONABRE Registry
}

\author{
Anouk K. M. Claessens ${ }^{1,2}$ • Bram L. T. Ramaekers ${ }^{3}$. Dorien J. A. Lobbezoo ${ }^{1} \cdot$ Roel J. W. van Kampen ${ }^{2} \cdot$ \\ Maaike de Boer ${ }^{1}$. Agnes J. van de Wouw ${ }^{4}$ M. Wouter Dercksen ${ }^{5} \cdot$ Sandra M. E. Geurts $^{1} \cdot$ Manuela A. Joore $^{3}$. \\ Vivianne C. G. Tjan-Heijnen ${ }^{1}$ (D)
}

Accepted: 5 August 2020 / Published online: 20 August 2020

(C) The Author(s) 2020

\begin{abstract}
Purpose We aimed to evaluate quality of life (QoL) using the European Quality of Life Five-Dimensions questionnaire (EQ-5D-3L) in a real-world cohort of Dutch advanced breast cancer (ABC) patients. Secondary, we reported differences in QoL between subgroups of patients based on age, comorbidity, tumor-, and treatment characteristics, and assessed the association of duration of metastatic disease and time to death with QoL.

Methods ABC patients who attended the outpatient clinic between October 2010 and May 2011 were asked to fill out the EQ-5D-3L questionnaire. Patient-, disease-, and treatment characteristics were obtained from the medical files. Health-utility scores were calculated. Subgroups were described and compared for utility scores by parametric and non-parametric methods. Results A total of 92 patients were included with a median utility score of 0.691 (Interquartile range [IQR] 0.244 ). Patients $\geq 65$ years had significantly worse median utility scores than younger patients; 0.638 versus 0.743 , respectively $(p=0.017)$. Moreover, scores were significantly worse for patients with versus those without comorbidity (medians 0.620 versus $0.725, p=0.005$ ). Utility scores did not significantly differ between subgroups of tumor type, type of systemic treatment, number of previous palliative treatment(s), or number or location of metastatic site(s). The remaining survival was correlated with utility scores (correlation coefficient $(r)=0.260, p=0.0252)$, especially in the subgroup $<65$ years $(r=0.340$, $p=0.0169)$, whereas there was no significant correlation with time since metastatic diagnosis $(r=-0.106, p=0.3136)$.

Conclusion Within this real-world cross-sectional study, QoL was significantly associated with age, comorbidity, and remaining survival duration. The observation of a lower QoL in $\mathrm{ABC}$ patients, possibly indicating the last period of life, may assist clinical decision-making on timing of cessation of systemic antitumor therapy.
\end{abstract}

Keywords Advanced breast cancer · Quality of life $\cdot$ EQ-5D $\cdot$ Real-world $\cdot$ Health utilities

\section{Background}

Advanced breast cancer (ABC), defined as metastatic breast cancer (stage IV), is a major cause of death among women worldwide [1]. Despite improving outcome of patients with $\mathrm{ABC}$ due to the introduction of new treatment agents and strategies, the disease remains largely incurable [2-4]. Thus, treatment focuses on both quality- and prolongation of life. Previous studies have shown that the quality of life (QoL) of these patients is positively associated with response to antitumor treatment, time to progression, and survival, but

Vivianne C. G. Tjan-Heijnen

vcg.tjan.heijnen@mumc.nl

Extended author information available on the last page of the article negatively associated with toxicity [5-8]. It is therefore essential to report on QoL in addition to clinical parameters to determine the health benefit of a new treatment.

There are different questionnaires suitable for evaluation of QoL among patients with $\mathrm{ABC}$ ranging from disease specific tools such as the European Organization for Research and Treatment for Cancer Quality of Life Questionnaire (EORTC QLQ-C30) to more generic instruments that allow comparison of QoL across diseases. Here we use the European Quality of Life FiveDimensions questionnaire (EQ-5D) to describe QoL and estimate a single summary index value rated on a scale from 0 (dead) to 1 (full health) [9]. The EQ-5D is the most widely used generic instrument to obtain such an utility score that reflects the overall health-state of 
participants according to the preferences of the general population of a country or region. In several European countries, this standardized questionnaire is preferred as a key component in cost-utility analysis $[10,11]$, and recently it was highlighted to be the most commonly cited multi-attribute utility instrument [12]. It has been used in clinical trials as well as observational studies for different types and stages of treatment of malignant diseases [13].

Despite the increased awareness of evaluation of QoL in addition to clinical outcomes, QoL and health-utility are underreported and not uniformly addressed in most breast cancer studies [8, 14-17]. Gaining insights into the QoL and the factors influencing this outcome is especially important for advanced stages of breast cancer, as the goal for these patients does comprise not only prolonging life, but also optimizing the QoL, considering treatments given in this disease stage are of palliative intend. Understanding which factors influence the QoL of these patients promotes individualized high-quality care. The primary aim of our analysis was to evaluate QoL by means of the EQ-5D in patients with $\mathrm{ABC}$ in a real-world Dutch cohort. In addition, we reported differences in QoL between subgroups of patients based on age, comorbidity, tumor-, and treatment characteristics, and assessed the association of duration of metastatic disease and time to death with QoL.

\section{Methods}

\section{Southeast Netherlands Advanced BREast cancer (SONABRE) Registry}

This study was part of the SONABRE Registry (NCT03577197), an ongoing real-world multi-center cohort study of $A B C$ patients. This registry aims to include all patients diagnosed with $A B C$ between 2007 and 2021 in 12 hospitals in the Southeast of the Netherlands. The study reported here was approved by the Medical Research Ethics Committee of Maastricht University Medical Center as part of the SONABRE Registry. Informed consent was obtained from all patients prior to inclusion.

\section{Study population}

Patients with ABC (stage IV disease) were identified from four hospitals participating in the SONABRE Registry, one academic and three teaching hospitals. Patients were eligible irrespective of being on active treatment or type of treatment. From October 2010 to May 2011, all ABC patients visiting the outpatient ward were invited by their treating oncologist to fill out the EQ-5D questionnaire, after general oral instruction during the informed consent procedure by their treating oncologist. They were invited only once, even if they attended the outpatient clinic more than once during the recruitment period.

\section{Data collection}

We used the Dutch version of the EQ-5D-3L questionnaire [13], which was provided by the medical oncologist after obtaining informed consent, and was filled out immediately. This questionnaire comprises five dimensions describing QoL on mobility, self-care, usual activities, pain/discomfort, and anxiety/depression. Each dimension has three answering categories: no problems (level 1), some problems (level 2), and extreme problems (level 3) [13]. We used country-specific tariffs to calculate the overall health-state utility score from the reported items [18]. Additionally, patient, disease, and treatment characteristics were obtained from the medical files by oncologists with experience in the treatment of breast cancer patients. Death and if applicable, date of death, was evaluated for all included patients in December 2016.

\section{Study endpoints and statistical analyses}

The primary study endpoint was to describe the health-utility score for the whole cohort. Previous studies on real-world QoL within breast cancer patients found several patient-, disease-, and treatment factors to exert a significant influence on the experienced QoL, including age [19, 20], comorbidities [20], type of therapy [19-24], number of lines of therapy [21, 24], location of metastases, [21, 22, 25], and disease progression [23, 26-28]. Therefor, our secondary endpoints included differences in QoL between subgroups of patients based on age ( $\geq 65$ versus $<65$ years), comorbidity according to the Charlson index (yes versus no and multiple subdivisions in comorbidity), tumor subtype (hormone receptor (HR) and human epidermal growth factor receptor-2 (HER2) status), current treatment type (endocrine, chemo- and/or targeted therapy), total number of prior palliative treatment lines, and number and metastatic site(s). As age has an influence on the experienced QoL also in the general population $[29,30]$, we reported the individual item scores of the EQ5D-3L questionnaire for age groups $\geq 65$ versus $<65$ years. Additionally, we assessed the association of duration of metastatic disease and time to death with QoL.

The metastatic-free interval was defined as the time between date of primary breast cancer diagnosis and the date of first diagnosis of metastatic disease. Time to death was defined as the time between the date of questionnaire completion and the date of death. Two patients alive at last follow-up were excluded from the time to death analysis.

Descriptive statistics were used to examine the individual item scores of the EQ-5D-3L questionnaire. The health-state utility scores were calculated using the item scores and the 
valuation function developed by Dolan et al. based on the time trade-off method [31]. Health-state utility scores could range from -0.594 to 1.000 , with negative scores implying health-states considered worse than death $[32,33]$. The minimum clinically important change or difference (MID) on the EQ-5D utility score was set at 0.03 , which is a widely used cutoff point [34].

Subgroups were compared using parametric (Student's t-tests) and non-parametric (Mann-Whitney-Wilcoxon test) methods, respectively, for comparing two subgroups and using one-way analysis of variance (ANOVA) and Kruskal-Wallis test, respectively, for comparisons of more than two groups.

For assessing correlations between utility scores and time of metastatic disease and time to death, the Pearson test was used to calculate a correlation coefficient $(r)$. The effect size of correlations was defined as weak $(r=0.20-0.39)$, moderate ( $r=0.40-0.59)$, or (very) strong $(r \geq 0.60-1.0)$ [35]. For all statistical tests, an alpha of 0.05 was assumed for statistical significance.

\section{Results}

\section{Patient, disease, and treatment characteristics}

A total of 92 patients completed the EQ-5D-3L questionnaire between October 2010 and May 2011. Most patients were younger than 65 years (65\%) and had no comorbidity (75\%) (Table 1). The median metastatic-free interval was 19.9 months (95\% confidence interval (CI) 13.1-26.8). Half of the patients (48\%) received prior (neo)adjuvant systemic therapy, and $93 \%$ of the patients were actively being treated. Most patients (73\%) had more than one metastatic site, in the majority of cases with visceral involvement. The median time to death counting from the date of questionnaire completion was 16.5 months (95\%CI 10.2-22.8). At last followup, 2 patients were still alive and 90 had deceased.

\section{Individual item scores}

For the dimensions mobility, usual activities, and pain/discomfort, most patients reported some problems (level 2), while for the dimensions self-care and anxiety/depression most patients reported no problems (level 1). For all dimensions, extreme problems (level 3) were scarcely reported, occurring most frequently in the dimensions usual activity (15\%) and pain/discomfort (10\%) (Table 2).

On all dimensions, but most prominent in mobility $(72 \%$ vs. $43 \%$ ), self-care (38\% vs. $17 \%$ ), and anxiety/depression ( $63 \%$ vs. $40 \%$ ), patients aged $\geq 65$ years reported level 2 or 3 problems more frequently compared to younger patients (Table 2). Specifically, extreme problems (level 3) regarding the usual activities and pain/discomfort dimensions were reported by, respectively, $28 \%$ and $19 \%$ of patients aged $\geq 65$ years, compared to $9 \%$ and $5 \%$ in the younger patient group. Overall, less than $10 \%$ of the younger patients reported severe problems on any of the dimensions.

\section{Utility scores}

The utility scores for the whole cohort were not normally distributed but skewed to the right, with a mean of 0.602 (SD 0.312) and a median of 0.691 (IQR 0.244) (data not further shown). Therefore, we report results accounting for this non-normal distribution, i.e., using the described nonparametric models. Notably, parametric models produced consistent results (Table 3).

There was a statistically significant difference between scores of patients aged $<$ and $\geq 65$ years (medians 0.743 versus $0.638 ; p=0.017$ ) (Table 3 ). Moreover, median utility scores were significantly worse for patients with versus those without comorbidity (yes versus no; 0.620 versus $0.725, p=$ $0.005)$. No statistically significant differences were observed between other subgroups.

No relation was identified between utility and time after metastatic disease diagnosis (Fig. 1; $r=-0.106, p=$ 0.3136 ) nor between utility and the number of prior lines of systemic therapy (data not shown). Interestingly, there was a positive relation between utility and the remaining survival time (Fig. 2; $r: 0.260, p=0.0252$ ), especially in the subgroup of patients of patients $<65$ years $(r: 0.340, p$ $=0.0169$ ).

\section{Discussion}

This cross-sectional study evaluated the QoL in real-life of $92 \mathrm{ABC}$ patients on different treatments (including no treatment). The median EQ-5D utility score was 0.691 (IQR 0.244 ), and differed significantly between subgroups based on age and the presence of comorbidity to both a statistically significant $(p<0.05)$ as well as a clinically relevant (difference in utilities $>0.03$ ) extend, to the detriment of patients aged $\geq 65$ years and patients with any comorbidity. Interestingly, we noticed a weak but significant positive correlation between the observed QoL and a patients' remaining survival time $(r=0.260, p=0.0252)$. Patients with a few months to live reported lower QoL as compared to those with a longer time to live, and this association was most clearly observed in the patients aged $<65$ years $(r=0.340$, $p=0.0169$ ).

In clinical practice, it is difficult to determine the prognosis of an individual patient accurately. The decision on whether to start a new treatment line in case of progression is based on the doctor's experience and perception and the 
Table 1 Patient, disease, and treatment characteristics (total $n=92$ )
Characteristic

No. of patients (\%)

Age (years)

$<65$

$60(65 \%)$

$\geq 65$

$32(35 \%)$

Comorbidity

No

$69(75 \%)$

Any

$23(25 \%)$

Cardiovascular

$11(12 \%)$

Diabetes

$4(4 \%)$

Lung disease

$5(5 \%)$

Cerebrovascular

$8(9 \%)$

Mobility

$10(11 \%)$

Hormone receptor status

Positive

$7784 \%)$

Negative

$15(16 \%)$

HER 2-status

Positive

$21(23 \%)$

Negative

$71(77 \%)$

Tumor characteristics

HR+/HER2-

$65(71 \%)$

HR+/HER2+

$12(13 \%)$

HR-/HER2+

$9(10 \%)$

HR-/HER2-

$6(7 \%)$

Prior (neo-)adjuvant systemic therapy

None

$48(2 \%)$

Endocrine therapy (with or without targeted therapy)

$24(26 \%)$

Chemotherapy (with or without targeted therapy)

$37(40 \%)$

Metastatic-free interval

De novo metastatic disease

$14(15 \%)$

$<24$ months

$10(11 \%)$

$\geq 24$ months

$68(74 \%)$

Total number of metastatic sites

$25(27 \%)$

$67(73 \%)$

$\geq 2$

$11(12 \%)$

$17(18 \%)$

$60(65 \%)$

$4(4 \%)$

Current treatment

None

$6(7 \%)$

Endocrine therapy (with or without targeted therapy)

$47(51 \%)$

Chemotherapy (with or without targeted therapy)

$34(37 \%)$

Targeted therapy alone

$5(5 \%)$

Number of palliative systemic treatments

1

$37(40 \%)$

$20(22 \%)$

$11(12 \%)$

$24(26 \%)$

$\geq 4$

$49(53 \%)$

$21(23 \%)$ 
Table 1 (continued)

\begin{tabular}{ll}
\hline Characteristic & No. of patients (\%) \\
\hline 3 & $9(10 \%)$ \\
$\geq 4$ & $13(14 \%)$ \\
Number of palliative chemotherapy lines & $62(67 \%)$ \\
1 & $11(12 \%)$ \\
2 & $11(12 \%)$ \\
3 & $8(9 \%)$ \\
$\geq 4$ & \\
Number of treatments (all, including neo/adjuvant therapy) & $25(27 \%)$ \\
1 & $17(18 \%)$ \\
2 & $14(15 \%)$ \\
3 & $36(39 \%)$ \\
\hline 4
\end{tabular}

${ }^{\text {a }}$ Sites of disease were classified in a mutually exclusive manner. Soft tissue localizations consisted of lymph nodes, skin and eye metastases. Visceral localizations consisted of liver, lung, pleura, peritoneum, gastrointestinal track, kidney and ovaries. Central Nervous System (CNS) localizations consisted of brain and leptomeningeal metastases

CNS Central Nervous System, No number, HER2 Human Epidermal growth factor 2-receptor, $H R$ hormone receptor, respectively, Estrogen or Progestogen-receptor

Table 2 Individual item scores of the EQ-5D questionnaire in a cross-sectional study of patients with advanced breast cancer by age

\begin{tabular}{|c|c|c|c|c|}
\hline & No problems/level 1 & $\begin{array}{l}\text { Some prob- } \\
\text { lems/level } 2\end{array}$ & $\begin{array}{l}\text { Extreme prob- } \\
\text { lems/level } 3\end{array}$ & $\begin{array}{l}\text { Total of some } \\
\text { and/or extreme } \\
\text { problems }^{\text {a }}\end{array}$ \\
\hline & $N(\%)$ & $N(\%)$ & $N(\%)$ & $N(\%)$ \\
\hline \multicolumn{5}{|l|}{ Mobility } \\
\hline All ages & $43(47 \%)$ & $47(51 \%)$ & $2(2 \%)$ & $49(53 \%)$ \\
\hline$<65$ years & $34(57 \%)$ & $25(41 \%)$ & $1(2 \%)$ & $26(43 \%)$ \\
\hline$\geq 65$ years & $928 \%)$ & $22(69 \%)$ & $1(3 \%)$ & $23(72 \%)$ \\
\hline \multicolumn{5}{|l|}{ Self-care } \\
\hline All ages & $70(76 \%)$ & $20(22 \%)$ & $2(2 \%)$ & $22(24 \%)$ \\
\hline$<65$ years & $50(83 \%)$ & $9(15 \%)$ & $1(2 \%)$ & $10(17 \%)$ \\
\hline$\geq 65$ years & $20(63 \%)$ & $11(34 \%)$ & $1(3 \%)$ & $12(38 \%)$ \\
\hline \multicolumn{5}{|c|}{ Usual activities } \\
\hline All ages & $22(24 \%)$ & $55(60 \%)$ & $14(15 \%)$ & $69(75 \%)$ \\
\hline$<65$ years & $16(27 \%)$ & $38(64 \%)$ & $5(9 \%)$ & $43(73 \%)$ \\
\hline$\geq 65$ years & $6(19 \%)$ & $17(53 \%)$ & $9(28 \%)$ & $26(81 \%)$ \\
\hline \multicolumn{5}{|c|}{ Pain/discomfort } \\
\hline All ages & $30(33 \%)$ & $53(58 \%)$ & $9(10 \%)$ & $62(67 \%)$ \\
\hline$<65$ years & $21(35 \%)$ & $36(60 \%)$ & $3(5 \%)$ & $39(65 \%)$ \\
\hline$\geq 65$ years & $9(28 \%)$ & $17(53 \%)$ & $6(19 \%)$ & $23(72 \%)$ \\
\hline \multicolumn{5}{|c|}{ Anxiety/depression } \\
\hline All ages & $48(52 \%)$ & $38(41 \%)$ & $6(7 \%)$ & $44(48 \%)$ \\
\hline$<65$ years & $36(60 \%)$ & $19(32 \%)$ & $5(8 \%)$ & $24(40 \%)$ \\
\hline$\geq 65$ years & $12(38 \%)$ & $19(59 \%)$ & $1(3 \%)$ & $20(63 \%)$ \\
\hline
\end{tabular}

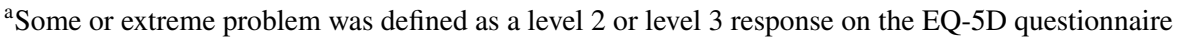
$n$ number of patients patient's preferences. The doctor's perception of the patient's wellbeing is reflected by the performance status ascribed to the general functioning of the patient. Indeed, performance status has shown to be related to treatment duration $[36,37]$ and overall survival [37-41] of patients with $A B C$ within real-world studies. The observation that QoL can also be 
Table 3 Utility scores by patient, disease, and treatment subgroups

\begin{tabular}{|c|c|c|c|c|c|c|c|}
\hline & No. of patients (\%) & Mean & SD & Median & IQR & $\begin{array}{l}p \text { value } \\
\text { Para-metric }\end{array}$ & $\begin{array}{l}p \text { value } \\
\text { Non-parametric }\end{array}$ \\
\hline All & $92(100 \%)$ & 0.602 & 0.312 & 0.691 & 0.244 & & \\
\hline \multicolumn{8}{|l|}{ Age } \\
\hline$<65$ year & $60(65 \%)$ & 0.660 & 0.271 & 0.743 & 0.194 & \multirow[t]{2}{*}{0.026} & \multirow[t]{2}{*}{0.017} \\
\hline$\geq 65$ year & $32(35 \%)$ & 0.494 & 0.359 & 0.638 & 0.463 & & \\
\hline \multicolumn{8}{|l|}{ Comorbidity } \\
\hline No & $69(75 \%)$ & 0.661 & 0.259 & 0.725 & 0.194 & \multirow[t]{2}{*}{0.012} & \multirow[t]{2}{*}{0.005} \\
\hline Yes & $23(25 \%)$ & 0.426 & 0.392 & 0.620 & 0.561 & & \\
\hline \multicolumn{8}{|l|}{ Tumor characteristics } \\
\hline HR+ HER2- & $65(71 \%)$ & 0.579 & 0.329 & 0.691 & 0.429 & \multirow[t]{4}{*}{0.499} & \multirow[t]{4}{*}{0.460} \\
\hline HR+ HER2+ & $12(13 \%)$ & 0.729 & 0.164 & 0.744 & 0.172 & & \\
\hline HR- HER2+ & $9(10 \%)$ & 0.616 & 0.383 & 0.691 & 0.071 & & \\
\hline HR - HER2- & $6(7 \%)$ & 0.574 & 0.227 & 0.575 & 0.239 & & \\
\hline \multicolumn{8}{|l|}{ Current treatment } \\
\hline No systematic treatment & $6(7 \%)$ & 0.734 & 0.137 & 0.743 & 0.107 & \multirow[t]{2}{*}{0.245} & \multirow[t]{2}{*}{0.196} \\
\hline Endocrine therapy (w/ or w/o targeted therapy) & $47(51 \%)$ & 0.601 & 0.302 & 0.691 & 0.209 & & \\
\hline \multicolumn{8}{|l|}{ Chemotherapy } \\
\hline (w/ or w/o targeted therapy) & $34(37 \%)$ & 0.550 & 0.354 & 0.661 & 0.344 & & \\
\hline Targeted therapy only & $5(5 \%)$ & 0.807 & 0.113 & 0.848 & 0.054 & & \\
\hline \multicolumn{8}{|l|}{ Number of treatment lines (all) } \\
\hline 1 & $37(40 \%)$ & 0.586 & 0.371 & 0.691 & 0.332 & \multirow[t]{4}{*}{0.439} & \multirow[t]{4}{*}{0.675} \\
\hline 2 & $20(22 \%)$ & 0.636 & 0.270 & 0.760 & 0.206 & & \\
\hline 3 & $11(12 \%)$ & 0.721 & 0.131 & 0.691 & 0.210 & & \\
\hline$\geq 4$ & $24(26 \%)$ & 0.544 & 0.303 & 0.630 & 0.343 & & \\
\hline \multicolumn{8}{|l|}{ Number of metastatic sites } \\
\hline 1 & $25(27 \%)$ & 0.629 & 0.333 & 0.689 & 0.192 & \multirow[t]{2}{*}{0.629} & \multirow[t]{2}{*}{0.722} \\
\hline$\geq 2$ & $67(73 \%)$ & 0.592 & 0.307 & 0.691 & 0.363 & & \\
\hline \multicolumn{8}{|l|}{ Type of metastatic sites } \\
\hline Bone only & $11(12 \%)$ & 0.594 & 0.273 & 0.623 & 0.096 & \multirow[t]{2}{*}{0.763} & \multirow[t]{4}{*}{0.737} \\
\hline Soft tissue w/o visceral or CNS involvement & $17(18 \%)$ & 0.532 & 0.450 & 0.691 & 0.209 & & \\
\hline Visceral w/o CNS involvement & 60 & $(65 \%)$ & 0.620 & 0.272 & 0.691 & 0.296 & \\
\hline Central Nervous System (CNS) & $4(4 \%)$ & 0.655 & 0.365 & 0.787 & 0.342 & & \\
\hline
\end{tabular}

No. number, $S D$ standard deviation, $I Q R$ interquartile range, HER2 Human Epidermal growth factor 2-receptor, HR hormone receptor, respectively, Estrogen or Progestogen-receptor, $w /$ with, w/o without

of assistance in guiding these decisions is interesting and should be further investigated in prospective studies.

Previous real-world studies among breast cancer patients using the EQ-5D report similar to slightly higher utility scores (median ranging from 0.64-0.82) [19, 20, 22, 24, $26,42,43]$ compared to our median (0.69). These differences in utility scores can partly be explained by the fact that most of these studies [22, 24, 26, 43] only included patients that were actively treated for their disease, leaving out the more vulnerable patients receiving supportive care. Additionally, the majority of these real-world studies [19, $20,24,42]$ also included patients with early breast cancer for which it can be expected that the QoL will be better due to less disease-related symptom burden. Furthermore, the mean age of patients within these trials varied, where studies with a lower mean age generally reported better utility scores; e.g., the study by Kim et al. reported a mean utility of 0.82 in a population with a median age of 49.3 years [43].

Factors found to have a significant association with QoL within previous observational studies for patients with breast cancer of various stages, including ABC, were age, [19, 20] fatigue, [19, 25, 26] financial difficulties, [19] pain, [19, 22, 25] body image, [25] comorbidities, [20],performance status, [23] type of therapy, [19-24] number of lines of therapy, $[21,24]$ location of metastases, [21, 22, 25], and disease progression [23, 26-28]. However, these associations were inconsistent, possibly due to differences in questionnaires used (EQ-5D, EORTC QLQ-C30 or -BR23, Patient Care 

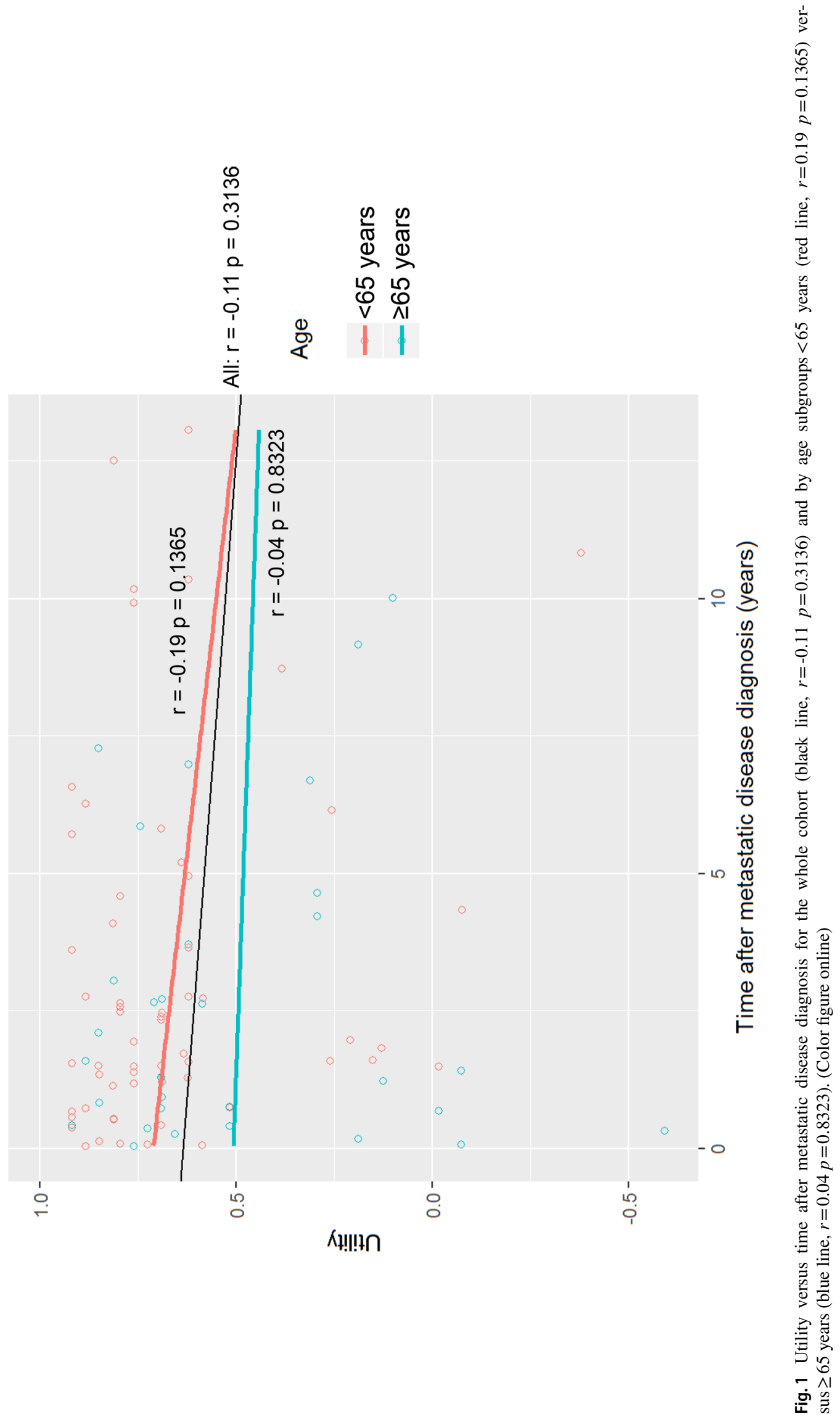
Fig. 2 Utility versus time to death*, for the whole cohort (black line, $r=0.26 p=0.0252$ ) and by age subgroups $<65$ years (red line, $r=0.34 p=0.0159$ ) versus $\geq 65$ years (blue line, $r=0.17 p=0.4304)$. *Only patients who deceased during the observation period were included. Two patients were still alive at last follow-up and were excluded from these analyses. (Color figure online)

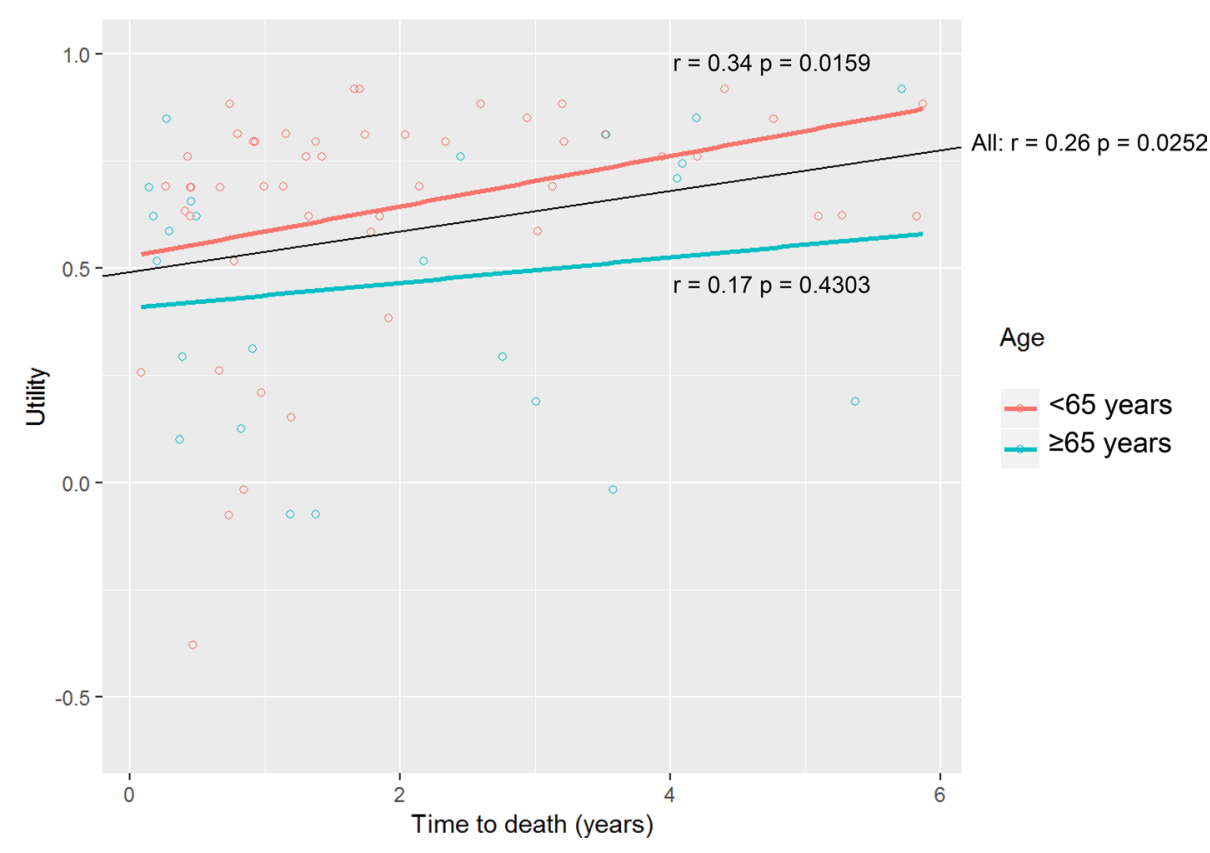

Monitor, FACT-B), population's health-related preferences, cultural dissimilarities, and methodology used in the valuation process [44]. Additionally, not all studies investigated the same variables, and within the investigated variables, impact varied between studies. This inconsistency in significance of the relation between the mentioned factors and the experienced QoL might be due to the lack of standardized methods, in combination with the observational nature of the studies.

Here, we found no association between the reported QoL and duration of metastatic disease and the number of prior lines of systemic therapy (data not shown). This stability of QoL with increasing number of treatment lines could be due to a correct selection of suitable patients for further therapy by their oncologists. Mostly, patients who are fit enough will be treated with further lines of treatment. Alternatively, the gradually increased therapeutic possibilities, the increased duration and amount of response to treatment resulting in better symptom control, could be an explanation of the lack of association between QoL and number of treatment lines.

The decision-making process on whether or not to continue treatment is also influenced by culture. Studies on EQ-5D value sets indicated that population-specific beliefs about health can contribute to differences in valuing a specific dimension of the EQ-5D as more or less important [44, 45]. Within a simulation study, Dutch respondents ascribed less weight than UK respondents to most dimensions of the EQ-5D, with the exception of the anxiety/depression dimension [45]. Another study comparing different value sets for the EQ-5D also found the Dutch value set was the only one out of 14 sets ascribing a worse health-state to a depressed patient compared to a patient with pain [44]. Several other studies among healthy as well as specific disease populations indicated that using different country-specific value sets produces substantially different results, and that despite a high level of correlation these tariffs cannot be used interchangeably [46-54]. More research is needed regarding the international transferability of utilities to ensure the economic evaluations underlying decision making are reliable and applicable to the intended population.

Thus, due to the large variation in methods used to assess QoL in breast cancer patients, [8, 14-16] there is a need for a more standardized approach. Therefore, the European guideline on the treatment of $\mathrm{ABC}$ urges the development of specific tools to evaluate QoL in ABC patients with attention to solid methodology [55]. The goal is to find a patient-centered way to measure QoL which incorporates the most relevant factors for patients, physicians, and decision makers with regard to drug approval and reimbursement. An important step forward is the central registration of patient-reported outcome data. For this purpose the EORTC Quality of Life Group developed a dedicated registry (PROMOTION) to identify, track, and analyze information about patient-reported outcomes (PRO), including QoL, of cancer patients included in randomized clinical trials since 2004 [56]. This database contains information regarding the assessment methodology, statistical design, and reported clinical and PRO results.

Our study is a cross-sectional study, and as a result changes in QoL during the disease course could not be investigated. Unfortunately, multivariate regression models were not performed due to the limited sample size of some subgroups and the skewness of the data. We intentionally mainly used descriptive statistics and (non)parametric tests, 
as regression models would be of limited usefulness in this case. Using a larger sample size and adopting multivariate regression models might be an informative step for future research to investigate a cause-effect relationship more profoundly. Furthermore, we only included patients that visited our outpatient clinic which could have led to an overestimation of the QoL scores. Finally, we did not have data on performance score and other possible relevant factors, such as toxicity. While highlighting the potential value of $\mathrm{QoL}$ in a similar role to performance status, such as in guiding patient decision making, correlation between the EQ-5D values and performance status assessments would have been worth mentioning. If highly correlated, using the EQ-5D could provide the advantage of covering more dimensions of QoL over the assessment of performance status. Conversely, performance score assessment is routinely done and might provide a quick and easy tool to guide decision-making. Strong points of our study are on the use of the preferred and validated generic instrument (EQ-5D), and that fact that our study is of important relevance for the ABC field, especially since it contains health-state utility data from routine clinical practice, which may be considered more representative data for guidance of decision-making than data from clinical trials.

In conclusion, within this real-world cross-sectional study, QoL was significantly associated with age, comorbidity, and remaining survival duration. The observation of a lower QoL in ABC patients, possibly indicating the last period of life, may assist clinical decision-making on timing of cessation of systemic antitumor therapy.

Acknowledgements We thank our SONABRE registrars of the department of Medical Oncology of Maastricht University Medical Center, Maastricht the Netherlands.

Author contributions All authors contributed to the study conception and design. Data collection and analysis were performed by RvK, BR, and AC. The first draft of the manuscript was written by RvK and AC and all authors commented on previous versions of the manuscript. All authors read and approved the final manuscript.

Funding This work was supported by the Netherlands Organization for Health Research and Development (ZonMw: 80-82500-98-8003), the division of Medical Oncology, Maastricht University Medical Center, Maastricht and Roche NL BV.

Data availability Additional information on the Southeast Netherlands Advanced BREast cancer (SONABRE) Registry can be found at the website of the U.S. National Library of Medicine, ClinicalTrials.gov, using identifier number NCT03577197.

\section{Compliance with ethical standards}

Conflict of interest A.K.M. Claessens: nothing to declare. B.L.T. Ramaekers: nothing to declare. D.J.A. Lobbezoo: Netherlands Organization for Health Research and Development (ZonMw: 80-82500-988003); Novartis BV; Roche; Pfizer. R.J.W. van Kampen: Netherlands
Organization for Health Research and Development (ZonMw: 8082500-98-8003). M. de Boer: Netherlands Organization for Health Research and Development (ZonMw: 80-82500-98-8003); Novartis BV; Roche; Pfizer; Eisai; Eli Lilly. A.J. van de Wouw: nothing to declare. M.W. Dercksen: nothing to declare. S.M.E. Geurts: Netherlands Organization for Health Research and Development (ZonMw: 80-8250098-8003); Novartis BV; Roche; Pfizer; Eli Lilly. M.A. Joore: nothing to declare. V.C.G. Tjan-Heijnen: Netherlands Organization for Health Research and Development (ZonMw: 80-82500-98-8003); Novartis BV; Roche; Pfizer; Eisai; E. Lilly.

Ethical approval The study reported here was approved by the Medical Research Ethics Committee of Maastricht University Medical Center as part of the SONABRE Registry.

Informed consent Informed consent was obtained from all patients prior to inclusion.

Open Access This article is licensed under a Creative Commons Attribution 4.0 International License, which permits use, sharing, adaptation, distribution and reproduction in any medium or format, as long as you give appropriate credit to the original author(s) and the source, provide a link to the Creative Commons licence, and indicate if changes were made. The images or other third party material in this article are included in the article's Creative Commons licence, unless indicated otherwise in a credit line to the material. If material is not included in the article's Creative Commons licence and your intended use is not permitted by statutory regulation or exceeds the permitted use, you will need to obtain permission directly from the copyright holder. To view a copy of this licence, visit http://creativecommons.org/licenses/by/4.0/.

\section{References}

1. Bray, F., Ferlay, J., Soerjomataram, I., Siegel, R. L., Torre, L. A., \& Jemal, A. (2018). Global cancer statistics 2018: GLOBOCAN estimates of incidence and mortality worldwide for 36 cancers in 185 countries. CA: A Cancer Journal for Clinicians, 68(6), 394-424. https://doi.org/10.3322/caac.21492.

2. Ruiterkamp, J., Ernst, M. F., de Munck, L., van der Heiden-van der Loo, M., Bastiaannet, E., van de Poll-Franse, L. V., et al. (2011). Improved survival of patients with primary distant metastatic breast cancer in the period of 1995-2008 A nationwide population-based study in the Netherlands. Breast Cancer Research and Treatment, 128(2), 495-501.

3. Noone, A., Howlader, N., Krapcho, M., Miller, D., Brest, A., Yu, M., et al. (2018). SEER Cancer Statistics Review 1975 - 2015. based on November 2017 SEER data submission, posted to SEER webiste April 18. Bethesda, MD: National Cancer Insitute.

4. Cardoso, F., Spence, D., Mertz, S., Corneliussen-James, D., Sabelko, K., Gralow, J., et al. (2018). Global analysis of advanced/ metastatic breast cancer: Decade report (2005-2015). The Breast, 39, 131-138. https://doi.org/10.1016/j.breast.2018.03.002.

5. Kramer, J. A., Curran, D., Piccart, M., de Haes, J. C., Bruning, P., Klijn, J., et al. (2000). Identification and interpretation of clinical and quality of life prognostic factors for survival and response to treatment in first-line chemotherapy in advanced breast cancer. European Journal of Cancer, 36(12), 1498-1506.

6. Efficace, F., Biganzoli, L., Piccart, M., Coens, C., Van Steen, K., Cufer, T., et al. (2004). Baseline health-related quality-of-life data as prognostic factors in a phase III multicentre study of women with metastatic breast cancer. European Journal of Cancer, 40(7), 1021-1030. https://doi.org/10.1016/j.ejca.2004.01.014. 
7. Quinten, C., Coens, C., Mauer, M., Comte, S., Sprangers, M. A., Cleeland, C., et al. (2009). Baseline quality of life as a prognostic indicator of survival: a meta-analysis of individual patient data from EORTC clinical trials. The lancet Oncology, 10(9), 865-871. https://doi.org/10.1016/s1470-2045(09)70200-1.

8. Montazeri, A. (2008). Health-related quality of life in breast cancer patients: a bibliographic review of the literature from 1974 to 2007. J Exp Clin Cancer Res, 29, 27-32. https://doi. org/10.1186/1756-9966-27-32.

9. Drummond, M. F., Sculpher, M. J., Claxton, K., Stoddart, G. L., \& Torrance, G. W. (2015). Methods for the Economical Evaluation of Health Care Programmes (4thth Edition ed.). Oxford: Oxford University Press.

10. EuroQolGroupHomepage. Retrieved July 2, 2019, from https:// euroqol.org/.

11. Longworth, L., Yang, Y., Young, T., Mulhern, B., Hernandez Alava, M., Mukuria, C., et al. (2014). Use of generic and condition-specific measures of health-related quality of life in NICE decision-making: A systematic review, statistical modelling and survey. Health Technology Assessment, 18(9), 1-224. https://doi. org/10.3310/hta18090.

12. Kennedy-Martin, M., Slaap, B., Herdman, M., van Reenen, M., Kennedy-Martin, T., Greiner, W., et al. (2020). Which multiattribute utility instruments are recommended for use in cost-utility analysis? A review of national health technology assessment (HTA) guidelines. The European Journal of Health Economics. https://doi.org/10.1007/s10198-020-01195-8.

13. EQ-5D-3L User Guide. (2018). Retrieved July 02, 2019, from https://euroqol.org/publications/user-guides/.

14. Bottomley, A., \& Therasse, P. (2002). Quality of life in patients undergoing systemic therapy for advanced breast cancer. The Lancet Oncology, 3(10), 620-628.

15. Ghislain, I., Zikos, E., Coens, C., Quinten, C., Balta, V., Tryfonidis, K., et al. (2016). Health-related quality of life in locally advanced and metastatic breast cancer: Methodological and clinical issues in randomised controlled trials. The Lancet Oncology, 17(7), e294-e304. https://doi.org/10.1016/S1470-2045(16)30099 $-7$.

16. Hao, Y., Wolfram, V., \& Cook, J. (2016). A structured review of health utility measures and elicitation in advanced/metastatic breast cancer. ClinicoEconomics and Outcomes Research, 23(8), 293-303. https://doi.org/10.2147/CEOR.S100448.

17. Adamowicz, K., Jassem, J., Katz, A., \& Saad, E. D. (2012). Assessment of quality of life in advanced breast cancer. An overview of randomized phase III trials. Cancer Treatment Reviews, 38(5), 554-558.

18. Brooks, R. G., Rabin, R., \& De Charro, F. (2010). The measurement and valuation of health status using EQ-5D: A European perspective: Evidence from the EuroQol BIOMED Research Programme. Dordrecht: Kluwer Academic Publishers.

19. Rautalin, M., Farkkila, N., Sintonen, H., Saarto, T., Taari, K., Jahkola, T., et al. (2018). Health-related quality of life in different states of breast cancer - comparing different instruments. Acta Oncologica, 57(5), 622-628. https://doi.org/10.1080/02841 86X.2017.1400683.

20. ACTIONStudyGroup. (2017). Health-related quality of life and psychological distress among cancer survivors in Southeast Asia: Results from a longitudinal study in eight low- and middle-income countries. BMC Medicine, 15(1), 10. https://doi.org/10.1186/ s12916-016-0768-2.

21. Wood, R., Mitra, D., de Courcy, J., \& Iyer, S. (2017). Patientreported Quality of Life and Treatment Satisfaction in Patients With HR(+)/HER2(-) Advanced/Metastatic Breast Cancer. Clinical Therapeutics, 39(8), 1719-1728. https://doi.org/10.1016/j. clinthera.2017.07.009.
22. Wood, R., Mitra, D., de Courcy, J., \& Iyer, S. (2017). Patientreported pain severity, pain interference and health status in $\mathrm{HR}+/$ HER2 - advanced/metastatic breast cancer. ESMO Open, 2(3), e000227. https://doi.org/10.1136/esmoopen-2017-000227.

23. Walker, M. S., Hasan, M., Yim, Y. M., Yu, E., Stepanski, E. J., \& Schwartzberg, L. S. (2011). Retrospective study of the effect of disease progression on patient reported outcomes in HER-2 negative metastatic breast cancer patients. Health and Quality of Life Outcomes. https://doi.org/10.1186/1477-7525-9-46.

24. Guerra, R. L., Dos Reis, N. B., Correa, F. M., Fernandes, M. M., Ribeiro Alves Fernandes, R., Cancela, M. C., et al. (2019). Breast cancer quality of life and health-state utility at a Brazilian Reference Public Cancer Center. Expert Review of Pharmacoeconomics and Outcomes Research. https://doi.org/10.1080/14737 167.2019.1621752.

25. McClelland, S. I., Holland, K. J., \& Griggs, J. J. (2015). Quality of life and metastatic breast cancer: The role of body image, disease site, and time since diagnosis. Quality of Life Research, 24(12), 2939-2943. https://doi.org/10.1007/s11136-015-1034-3.

26. Lambert-Obry, V., Gouault-Laliberte, A., Castonguay, A., Zanotti, G., Tran, T., Mates, M., et al. (2018). Real-world patient- and caregiver-reported outcomes in advanced breast cancer. Current Oncology, 25(4), e282-e290. https://doi.org/10.3747/co.25.3765.

27. Müller, V., Nabieva, N., Haberle, L., Taran, F. A., Hartkopf, A. D., Volz, B., et al. (2018). Impact of disease progression on healthrelated quality of life in patients with metastatic breast cancer in the PRAEGNANT breast cancer registry. Breast, 37, 154-160. https://doi.org/10.1016/j.breast.2017.08.008.

28. Oh, S., Heflin, L., Meyerowitz, B. E., Desmond, K. A., Rowland, J. H., \& Ganz, P. A. (2004). Quality of life of breast cancer survivors after a recurrence: A follow-up study. Breast Cancer Research and Treatment, 87(1), 45-57. https://doi.org/10.1023/ B:BREA.0000041580.55817.5a.

29. Mangen, M. J., Bolkenbaas, M., Huijts, S. M., van Werkhoven, C. H., Bonten, M. J., \& de Wit, G. A. (2017). Quality of life in community-dwelling Dutch elderly measured by EQ-5D-3L. Health and Quality of Life Outcomes. https://doi.org/10.1186/ s12955-016-0577-5.

30. Nolte, S., Liegl, G., Petersen, M. A., Aaronson, N. K., Costantini, A., Fayers, P. M., et al. (2019). General population normative data for the EORTC QLQ-C30 health-related quality of life questionnaire based on 15,386 persons across 13 European countries, Canada and the Unites States. European Journal of Cancer, 107, 153-163. https://doi.org/10.1016/j.ejca.2018.11.024.

31. Dolan, P. (1997). Modeling valuations for EuroQol health states. Medical Care, 35(11), 1095-1108.

32. Brooks, R. (1996). EuroQol: the current state of play. Health Policy, 37(1), 53-72.

33. EuroQolGroup. (1990). EuroQol-a new facility for the measurement of health-related quality of life. Health Policy, 16(3), 199-208.

34. Marra, C. A., Woolcott Jc Fau - Kopec, J. A., Kopec Ja Fau Shojania, K., Shojania K Fau - Offer, R., Offer R Fau - Brazier, J. E., Brazier Je Fau - Esdaile, J. M., et al. A comparison of generic, indirect utility measures (the HUI2, HUI3, SF-6D, and the EQ-5D) and disease-specific instruments (the RAQoL and the HAQ) in rheumatoid arthritis. (0277-9536 (Print)).

35. Cohen, J., Cohen, P., West, S. G., \& Aiken, L. S. (2003). Applied multiple regression/correlation analysis for the behavioral sciences. New York: Routlegde.

36. Dranitsaris, G., Beegle, N., Kalberer, T., Blau, S., Cox, D., \& Faria, C. (2015). A comparison of toxicity and health care resource use between eribulin, capecitabine, gemcitabine, and vinorelbine in patients with metastatic breast cancer treated in a community oncology setting. Journal of Oncology Pharmacy 
Practice, 21(3), 170-177. https://doi.org/10.1177/1078155214 525369.

37. Xie, J., Hao, Y., Li, N., Lin, P. L., Ohashi, E., Koo, V., et al. (2015). Clinical outcomes among HR+/HER2- metastatic breast cancer patients with multiple metastatic sites: A chart review study in the US. Experimental Hematology and Oncology, 12(4), 31. https://doi.org/10.1186/s40164-015-0023-0.

38. Pentheroudakis, G., Fountzilas, G., Bafaloukos, D., Koutsoukou, V., Pectasides, D., Skarlos, D., et al. (2006). Metastatic breast cancer with liver metastases: a registry analysis of clinicopathologic, management and outcome characteristics of 500 women. Breast Cancer Research and Treatment, 97(3), 237-244. https:// doi.org/10.1007/s10549-005-9117-4.

39. Kurosky, S. K., Mitra, D., Zanotti, G., \& Kaye, J. A. (2018). Treatment patterns and outcomes of patients with metastatic ER(+)/ HER-2(-) breast cancer: A multicountry retrospective medical record review. Clinical Breast Cancer, 18(4), e529-e538. https:// doi.org/10.1016/j.clbc.2017.10.008.

40. Cinausero, M., Gerratana, L., De Carlo, E., Iacono, D., Bonotto, M., Fanotto, V., et al. (2018). Determinants of last-line treatment in metastatic breast cancer. Clinical Breast Cancer, 18(3), 205213. https://doi.org/10.1016/j.clbc.2017.07.008.

41. Galy, G., Labidi-Galy, S. I., Perol, D., Bachelot, T., Ray-Coquard, I., Tredan, O., et al. (2011). Chemotherapy for metastatic breast cancer. Comparison of clinical practice and cost of drugs in two cohorts of patients: 1994-1998 and 2003-2006. Breast Cancer Research and Treatment, 128(1), 187-195.

42. Lidgren, M., Wilking, N., Jönsson, B., \& Rehnberg, C. (2007). Health related quality of life in different states of breast cancer. Quality of Life Research, 16(6), 1073-1081. https://doi. org/10.1007/s11136-007-9202-8

43. Kim, E. J., Ko, S. K., \& Kang, H. Y. (2012). Mapping the cancer-specific EORTC QLQ-C30 and EORTC QLQ-BR23 to the generic EQ-5D in metastatic breast cancer patients. Quality of Life Research, 21(7), 1193-1203. https://doi.org/10.1007/s1113 6-011-0037-y.

44. Knies, S., Evers Sm Fau - Candel, M. J. J. M., Candel Mj Fau Severens, J. L., Severens Jl Fau - Ament, A. J. H. A., \& Ament, A. J. Utilities of the EQ-5D: transferable or not? (1170-7690 (Print)).

45. Lamers, L. M., McDonnell, J., Stalmeier, P. F. M., Krabbe, P. F. M., \& Busschbach, J. J. (2006). The Dutch tariff: results and arguments for an effective design for national EQ-5D valuation studies. Health Economics, 15(10), 1121-1132. https://doi. org/10.1002/hec. 1124 .

46. Liu, L., Li, S., Wang, M., \& Chen, G. (2017). Comparison of EQ-5D-5L health state utilities using four country-specific tariffs on a breast cancer patient sample in mainland China. Patient Prefer Adherence, 23(11), 1049-1056. https://doi.org/10.2147/PPA. S138028.

47. Karlsson, J. A., Nilsson, J. F., Neovius, M., Kristensen, L., Gulfe, A., Saxne, T., et al. (2011). National EQ-5D tariffs and qualityadjusted life-year estimation: Comparison of UK, US and Danish utilities in south Swedish rheumatoid arthritis patients. Annals of the Rheumatic Diseases, 70(12), 2163-2166. https://doi. org/10.1136/ard.2011.153437.

48. Zhao, Y., Li, S. P., Liu, L., Zhang, J. L., \& Chen, G. (2017). Does the choice of tariff matter?: A comparison of EQ-5D-5L utility scores using Chinese, UK, and Japanese tariffs on patients with psoriasis vulgaris in Central South China. Medicine (Baltimore), 96(34), e7840. https://doi.org/10.1097/MD.0000000000007840.

49. Kiadaliri, A. A., Eliasson, B., \& Gerdtham, U. G. (2015). Does the choice of EQ-5D tariff matter? A comparison of the Swedish EQ5D-3L index score with UK, US, Germany and Denmark among type 2 diabetes patients. Health and Quality of Life Outcomes, 15(13), 145. https://doi.org/10.1186/s12955-015-0344-z.

50. Mozzi, A., Meregaglia, M., Lazzaro, C., Tornatore, V., Belfiglio, M., \& Fattore, G. (2016). A comparison of EuroQol 5-Dimension health-related utilities using Italian, UK, and US preference weights in a patient sample. ClinicoEconomics and Outcomes Research, 13(8), 267-274. https://doi.org/10.2147/CEOR.S98226.

51. Busschbach, J. J., Weijnen, T., Nieuwenhuizen, M., Oppe, S., Badia, X., Dolan, P., et al. (2003). A comparison of EQ-5D time trade-off values obtained in Germany, the United Kingdom and Spain. In R. Brooks, R. Rabin, \& F. de Charro (Eds.), The measurement and valuation of health status using EQ-5D: A European perspective (pp. 143-165). Dordrecht: Kluwer Academic Publishers.

52. Badia, X., Roset, M., Herdman, M., \& Kind, P. (2001). A comparison of United Kingdom and Spanish general population time trade-off values for EQ-5D health states. Medical Decision Making, 21(1), 7-16. https://doi.org/10.1177/0272989X0102100102.

53. Luo, N., Johnson, J. A., Shaw, J. W., \& Coons, S. J. (2007). A comparison of EQ-5D index scores derived from the US and UK population-based scoring functions. Medical Decision Making, 27(3), 321-326. https://doi.org/10.1177/0272989X07300603.

54. Szende, A., Oppe, M., \& Devlin, N. (2007). EQ-5D value sets: Inventory, comparative review and user guide. Dordrecht: Springer.

55. Cardoso, F., Senkus, E., Costa, A., Papadopoulos, E., Aapro, M., Andre, F., et al. (2018). 4th ESO-ESMO International Consensus Guidelines for Advanced Breast Cancer (ABC 4). Annals of Oncology, 29(8), 1634-1657. https://doi.org/10.1093/annonc/ mdy192.

56. Efficace, F., Rees, J., Fayers, P., Pusic, A., Taphoorn, M., Greimel, E., et al. (2014). Overcoming barriers to the implementation of patient-reported outcomes in cancer clinical trials: the PROMOTION Registry. Health Quality and Life Outcomes, 12, 86. https ://doi.org/10.1186/1477-7525-12-86.

Publisher's Note Springer Nature remains neutral with regard to jurisdictional claims in published maps and institutional affiliations.

\section{Affiliations}

\section{Anouk K. M. Claessens ${ }^{1,2}$ - Bram L. T. Ramaekers ${ }^{3}$. Dorien J. A. Lobbezoo ${ }^{1} \cdot$ Roel J. W. van Kampen ${ }^{2}$. Maaike de Boer ${ }^{1}$. Agnes J. van de Wouw ${ }^{4} \cdot$ M. Wouter Dercksen ${ }^{5}$. Sandra M. E. Geurts ${ }^{1} \cdot$ Manuela A. Joore ${ }^{3}$. Vivianne C. G. Tjan-Heijnen ${ }^{1}[1$}

Anouk K. M. Claessens

anouk.claessens.91@gmail.com

Bram L. T. Ramaekers

bram.ramaekers@mumc.nl
Dorien J. A. Lobbezoo

d.lobbezoo@mumc.nl

Roel J. W. van Kampen

r.vankampen@zuyderland.nl 
Maaike de Boer

maaike.de.boer@mumc.nl

Agnes J. van de Wouw yvdwouw@viecuri.nl

M. Wouter Dercksen

m.dercksen@mmc.nl

Sandra M. E. Geurts

sandra.geurts@mumc.nl

Manuela A. Joore

m.joore@mumc.nl

1 Department of Medical Oncology, GROW-School for Oncology and Developmental Biology, Maastricht
University Medical Center, PO BOX 5800,

6202 AZ Maastricht, The Netherlands

2 Department of Medical Oncology, Zuyderland Medical Center, PO BOX 5500, 6130 MB Sittard-Geleen,

The Netherlands

3 Department of Clinical Epidemiology and Medical Technology Assessment (KEMTA), Maastricht University Medical Centre, PO BOX 5800, 6202 AZ Maastricht, The Netherlands

4 Department of Internal Medicine, VieCuri Medical Center, PO BOX 1926, 5900 BX Venlo, The Netherlands

5 Department of Internal Medicine, Máxima Medical Center, PO BOX 90052, 5600 PD Eindhoven, The Netherlands 